\title{
Micellization of Polyoxyethylene-Polyoxypropylene Block Copolymers in Aqueous Polyol Solutions
}

\author{
Kazuhiro Kaizu ${ }^{1}$ and Paschalis Alexandridis* \\ Department of Chemical and Biological Engineering \\ University at Buffalo, The State University of New York (SUNY) \\ Buffalo, NY 14260-4200, USA
}

(1) On leave from: Skin Care Labs, Kao Corp., Tokyo 131-8501, Japan

*To whom correspondence should be addressed

phone: (716) 645-1183

e-mail: palexand@buffalo.edu 


\begin{abstract}
The micellization of a representative polyoxyethylene-polyoxypropylene-
\end{abstract} polyoxyethylene (POE-POP-POE) amphiphilic block copolymer (Pluronic P105, $\mathrm{EO}_{37} \mathrm{PO}_{58} \mathrm{EO}_{37}$ ) in aqueous solutions of the common excipients glucose, glycerol or ethanol, has been investigated as a function of solute (solvent) concentration, block copolymer concentration, and temperature. The formation of POE-POP-POE micelles is favored in the presence of glucose or glycerol, while ethanol has the opposite effect. $\Delta \mathrm{H}^{\circ}$ and $\Delta \mathrm{S}^{\circ}$ values derived from analysis of critical micellization concentration (CMC) data are both positive in all mixed aqueous polyol systems. $\Delta \mathrm{H}^{\circ}$ and $\Delta \mathrm{S}^{\circ}$ decrease slightly with increasing glucose or glycerol content, but increase significantly in the presence of ethanol. A 10- to 100-fold increase of the amphiphilic block copolymer solution viscosity was observed in the presence of glucose or glycerol above a certain temperature. This viscosity increase is indicative of micelle shape changes from spherical to elongated. The CMC and viscosity changes caused by glucose and glycerol are attributed to the enhanced dehydration of the POE block of the polymeric amphiphile. Glucose is more effective than glycerol, apparently due to its higher hydration number.

Keywords: block copolymer; Poloxamer; poly(ethylene oxide) (PEO); poly(propylene oxide) (PPO); glucose; formulation; excipient. 


\section{Introduction}

The ability of amphiphiles to self-assemble in aqueous solutions is integral in a variety of products, e.g., pharmaceutics, skin-care, hair-care, detergents, coatings and inks. Therefore, the elucidation of the self-assembly behavior of amphiphiles under different conditions is of great interest for industrial applications and also for fundamental considerations. Micellar solutions, which are the most common self-assembling systems, have been extensively researched. Several reports have considered solvent effects on micelle formation and structure, the solvent quality being a controlling factor for amphiphile self-assembly. ${ }^{1}$

The most commonly examined solvent additives are alcohols and also polyols ${ }^{1}$. Addition of alcohol to aqueous surfactant solutions can result in changes of, e.g., critical micellization concentration (CMC), critical micellization temperature (CMT), micelle molecular weight or association number, micelle radius, micelle shape, and ionization degree or surface density of micelle. These changes are attributed to a decrease of the solution dielectric constant caused by alcohols, and to alcohol penetration in the micelle hydrophobic interior ${ }^{1,2,3}$. In the case of polyoxyethylene (POE)-containing nonionic surfactants, the dehydration of POE that is effected by added polyols becomes also important ${ }^{4,5,6}$.

These factors lend complexity to aqueous surfactant systems containing alcohols. For example the effect of ethanol on the CMC of sodium dodecyl sulfate (SDS) or tetradecyltrimethylammonium bromide (TTAB) aqueous solution at $25^{\circ} \mathrm{C}$ is non-monotonic: the CMC goes through a minimum at around $4.8 \mathrm{wt} \%$ ethanol and then increases with further increase of the ethanol content ${ }^{1}$. On the other hand, in the case of POE(31)-dodecyl ether, the CMC simply increases with increasing ethanol content at $20^{\circ} \mathrm{C}^{\mathbf{1}}$. The micelle size decreases and the micelles eventually disappear when sufficient amount of ethanol is added to $\operatorname{SDS}^{\mathbf{1}}$ (around $19 \mathrm{wt} \%$ ethanol) or to cetyltrimethylammonium bromide aqueous solution ${ }^{7}$ (around 80 
vol\% ethanol). In another example, the addition of glycerol to $\mathrm{SDS}^{\mathbf{8}, \mathbf{9}}$ or $\mathrm{TTAB}^{\mathbf{1 0}}$ aqueous solutions at $25{ }^{\circ} \mathrm{C}$ and to POE(8)-dodecyl ether ${ }^{11}$ aqueous solution in the temperature range 25 $35{ }^{\circ} \mathrm{C}$ leads to an increase in CMC. Moreover, the addition of glycerol to POE(8)-hexadecyl ether results in a shape change of the micelles from spherical to rod-like ${ }^{4}$.

We have an on-going interest in our research group on solvent quality effects on the conformation and supramolecular organization of polymeric amphiphiles such as polyoxyethylene-polyoxypropylene-polyoxyethylene (POE-POP-POE) block copolymers (which are commercially available as Pluronics or Poloxamers), poly(dimethylsiloxane)-graft-polyether copolymers, and polysaccharides (e.g., dextran, cellulose ethers). We have shown that the structural polymorphism of polymeric surfactants is richer than that of typical, low molecular weight surfactants ${ }^{12,13}$. Even in dilute solutions, polymeric surfactants have the potential to exhibit complex structures such as flower-like or star-like assemblies ${ }^{\mathbf{1 6}}$ due to the conformational flexibility conferred by their higher molecular weight and corresponding length.

We have previously reported on the effects of polar organic solvents such as formamide, ethanol, and glycerol on the self-assembly of a POE-POP-POE block copolymer (Pluronic P105, $\left.\mathrm{EO}_{37} \mathrm{PO}_{58} \mathrm{EO}_{37}\right)$ in aqueous solutions, determined from analysis of small-angle neutron scattering (SANS) measurements ${ }^{5,15}$. We found that the addition of formamide or ethanol led to a decrease in the micelle size and the polymer volume fraction in the micelle corona and core, and an increase in the CMC, while glycerol caused the opposite trend ${ }^{5,15}$. Other groups have reported the effect of 1-butanol on Pluronic F127 ( $\left.\mathrm{EO}_{99} \mathrm{PO}_{65} \mathrm{EO}_{99}\right)$ aqueous solutions ${ }^{\mathbf{1 6}}$, and of 1-pentanol on Pluronic P103 $\left(\mathrm{EO}_{17} \mathrm{PO}_{60} \mathrm{EO}_{17}\right), \quad \mathrm{P} 105 \quad\left(\mathrm{EO}_{37} \mathrm{PO}_{58} \mathrm{EO}_{37}\right)$, and P108 $\left(\mathrm{EO}_{132} \mathrm{PO}_{50} \mathrm{EO}_{132}\right)$ aqueous solutions ${ }^{17}$. Both 1-butanol and 1-pentanol decrease the CMC and solubilize in the micelle core ${ }^{\mathbf{1 7}}$, in agreement with our observations.

We have also reported on the effects of 2-propanol, ethanol, formamide and glycerol on 
micelles formed by poly(dimethylsiloxane)-graft-polyether copolymers in aqueous solutions. The micelle radii, micelle association numbers, and polymer volume fractions in the micelle corona and core decreased with increasing 2-propanol, ethanol, or formamide content. On the contrary, the addition of glycerol led to an increase of the micelle association number and caused a micelle shape change from sphere to ellipse $^{6}$. Similar shape changes in poly(dimethylsiloxane)-graft-polyether micelles have been reported upon the addition of glucose, 2-butoxyethanol, and polyoxyethylene ${ }^{18}$. It is notable that we found a good correlation between the CMC in the presence of various solvents and the component of the solvent solubility parameter $(\delta)$ which accounts for hydrogen bonding ${ }^{19,20}$.

Here we focus our attention on polyols such as glucose and glycerol which are widely used as excipients in pharmaceutical, cosmetic, and food formulations ${ }^{21,22}$. We examine the effects of these polyols on the micellization in water of a representative POE-POP-POE block copolymer (Pluronic P105, $\mathrm{EO}_{37} \mathrm{PO}_{58} \mathrm{EO}_{37}$ ). In particular, we present information on (i) micelle formation, (ii) thermodynamics of micellization, and (iii) micelle solution properties in aqueous glucose or glycerol solutions, as well as in aqueous mixtures of glucose and ethanol.

\section{Materials and Methods}

\section{Materials}

The Pluronic P105 polyoxyethylene-polyoxypropylene-polyoxyethylene (POE-POP-POE) block copolymer was obtained from BASF Corp. and was used as received. According to the manufacturer it has molecular weight of 6500 and $50 \mathrm{wt} \%$ PEO content and can thus be represented as $\mathrm{EO}_{37} \mathrm{PO}_{58} \mathrm{EO}_{37}$. Among the various POE-POP-POE block copolymers available commercially, Pluronic P105 is of intermediate hydrophobic/hydrophilic balance and molecular weight. Not coincidentally it exhibits a rich phase behavior in the presence of water 
and/or non-aqueous polar solvents ${ }^{23-25}$. $\mathrm{D}(+)$-glucose monohydrate $(>99.5 \%)$ was purchased from Fluka Chemical Corp., Milwaukee, WI. Glycerol anhydrous (>99.5) was purchased from J. T. Baker, Phillipsburg, NJ. Ethyl alcohol (99.5\%) was purchased from Pharmco Products Inc., Brookfield, CT. Millipore-filtered water was used for all samples, which were prepared by weighing appropriate amounts of polymer, solute and water. Appropriate time was allowed for thermodynamic equilibration of the samples. Chemical formulas for the molecules considered here are shown in Fig. 1, and physicochemical parameters are presented in Table 1.

\section{Light scattering}

The light scattering intensity of samples was measured with a Brookhaven BI-200SM goniometer (equipped with a Lexel model 95 argon ion laser operating at $514 \mathrm{~nm}$ ) at $90^{\circ}$ detection angle at temperatures varying in the range $5-45^{\circ} \mathrm{C}$. Previously equilibrated samples were kept an hour at a specific temperature before measurements. The sample compositions are the following: Pluronic P105 content $=1$ or $8 \mathrm{wt} \%$, solute or solvent (glucose monohydrate, glycerol, or ethanol) content $=0,20,30,40$, or $60 \mathrm{wt} \%$, and the remainder is water.

\section{Viscosity}

Viscosities of aqueous Pluronic P105 solutions were measured with a Cannon-Fenske routine type viscometer at the temperature range $7-60{ }^{\circ} \mathrm{C}{ }^{\mathbf{2 0}}$. The reproducibility of viscosity values was typically $\pm 3 \%$. Above certain temperatures the viscosities of these solutions increased dramatically (more than 10-fold), and the measurements in this case were subject to bigger error. The sample compositions that we considered are: 1 or 8 wt\% Pluronic P105, 0, 20, 30, or $40 \mathrm{wt} \%$ glucose monohydrate or glycerol, or 5, $10 \mathrm{wt} \%$ ethanol, with the remainder being water. The reported relative viscosity denotes the viscosity of the aqueous Pluronic P105 
solutions divided by the viscosity of the correspondent solvents (consisting of aqueous solutions of glucose, glycerol, or glucose + ethanol, or plain water).

\section{Phase behavior}

We have already reported ternary isothermal $\left(25^{\circ} \mathrm{C}\right)$ phase diagrams for Pluronic P105 water - glucose, glycerol, or ethanol systems²4. Normal (“oil”-in-“water”) isotropic micellar solutions as well as micellar cubic, normal hexagonal, normal bicontinuous cubic, and lamellar lyotropic liquid crystalline (LLC) phases have been identified in these phase diagrams. The LLC structures "dissolve" with increasing ethanol content above $25 \%$. It is notable that, with increasing glucose or glycerol content relative to water, the composition range of the normal hexagonal (cylindrical) LLC region expands toward lower block copolymer contents. This signifies a decrease in interfacial curvature (from sphere to cylinder). On the basis of these findings ${ }^{24}$, we can expect that at elevated temperatures the formation of normal hexagonal lyotropic liquid crystalline structure will take place at lower block copolymer content and/or glucose or glycerol content.

Motivated by the above, we checked the samples under polarized light for possible optical anisotropy, indication of hexagonal or lamellar LLC structure. All samples examined and reported here were transparent and one-phase in the temperature range $7-60{ }^{\circ} \mathrm{C}$. Some birefringence was observed only at the composition Pluronic P105 (8 wt\%) - glucose monohydrate (40 wt\%) - water (52 wt\%), at 55 and $60^{\circ} \mathrm{C}$ (we do not report data for these conditions here). This slight birefringence became more pronounced when the sample was shaken by hand. This could be suggestive of the formation of a nematic phase of elongated micelles $^{26,27}$, which may be intermediate between the micellar solution and the hexagonal LLC phase. 


\section{Results and Discussion}

\section{Micelle formation}

In aqueous solution POP-POE-POP block copolymers can self-assemble into micelles with the core dominated by the relatively hydrophobic POP blocks and the corona dominated by hydrated POE blocks. The aqueous solubility of these blocks is dependent on temperature, therefore the self-assembly of POE-POP-POE block copolymers is very sensitive to temperature, contrary to that of typical nonionic surfactants ${ }^{28,29}$. Such amphiphilic block copolymers can form micelles above a certain solution temperature (CMT), in addition to forming micelles above a certain block copolymer concentration (CMC). Thus one can ascertain the micelle formation from either CMT or CMC measurements ${ }^{30}$. In this study we conducted CMT measurements because they have the advantage of using the same samples at varying temperature, thus eliminating a possible source of experimental uncertainty. We determined the CMT from changes of the light scattering intensity vs. temperature, since the micelles scatter light much more strongly than the unassociated polymers (unimers) ${ }^{30}$.

The CMTs of ternary Pluronic P105 (1 or 8 wt\%) - solute or solvent (glucose monohydrate, glycerol, or ethanol) (0, 20, 30, $40 \mathrm{wt} \%)$ - water solutions are reported in Fig. 2. The lines connecting the CMT-CMC points can be viewed as the micellization phase boundaries $^{30}$. At temperatures and block copolymer concentrations below the micellization boundary, the block copolymers do not associate (but remain free in solution as unimers). At temperatures and concentrations above the micellization boundary, the block copolymers self-assemble to form micelles (that are in equilibrium with unimers). In the case of the glucose and glycerol solutions, the micellization boundaries shift toward the low left corner of the diagrams, whereas ethanol has the opposite effect. This demonstrates that glucose and glycerol 
promote the formation of micelles, but ethanol does not.

The CMT decrease with increasing glucose content in the systems considered here is consistent with previously reported cases: the addition of glucose to $\operatorname{SDS}^{31,}{ }^{32}$,

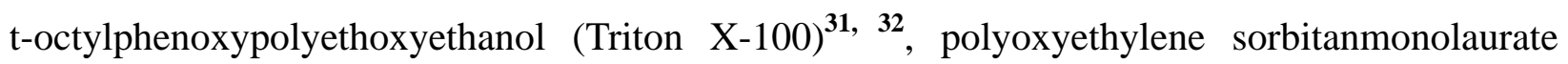
$\left(\right.$ Tween 20) ${ }^{32}$, or poly(dimethylsiloxane)-graft-polyether ${ }^{19}$ aqueous solutions led to a decrease in CMC, a shift to lower temperature of the gel-sol transition for poly(2-ethyl-2-oxazoline)-poly( $\varepsilon$-caprolactone) block copolymer aqueous solutions ${ }^{33}$, and a lowering of the cloud point of polyoxyethylene (PEG 20000) aqueous solution ${ }^{34}$. More specifically, addition of $5 \mathrm{wt} \%$ glucose in aqueous surfactant solutions at $25{ }^{\circ} \mathrm{C}$ caused a CMC decrease from 0.029 to $0.017 \mathrm{wt} \%$ for SDS, from 0.037 to $0.025 \mathrm{wt} \%$ for Tween 20 , and from 0.032 to $0.026 \mathrm{wt} \%$ for Triton $\mathrm{X}-100^{32}$. This tendency may be attributed to the dehydration of POE caused by glucose ${ }^{4,5,6,19,35}$.

The POE-POP-POE block copolymer CMT decrease with increasing glycerol content is consistent with previous research on the same system (up to $20 \mathrm{vol} \%$ glycerol) ${ }^{5}$, but opposite to what has been observed for typical surfactants: the addition of glycerol to $\mathrm{SDS}^{8,9}$, $\mathrm{TTAB}^{\mathbf{1 0}}$ or POE(8)-dodecyl ether ${ }^{11}$ aqueous solutions caused an increase in CMC. This increase in CMC upon adding glycerol can be due to the weakening of the hydrophobic interactions ${ }^{31}$ following a decrease of the solution dielectric constant ${ }^{1}$. In the case of POE-POP-POE block copolymer aqueous solutions, POE dehydration effected by glycerol ${ }^{4,5,6,19,35}$ appears more effective than a possible weakening of the hydrophobic interactions ${ }^{31}$, and leads to a CMC or CMT decrease.

\section{Comparison of glucose and glycerol effects on micellization relative to the number of $\mathrm{OH}$ groups}

The $\mathrm{OH}$ groups of solutes or solvents present in aqueous solutions play an important 
role on micellization. It has been reported that the effects of alcohols (methanol, ethylene glycol, or glycerol) on the CMC of SDS aqueous solutions depend on the number of $\mathrm{OH}$ groups and not on the number of alcohol molecules when their concentration are relatively low (around $5 \mathrm{wt} \%)$. For the same number of $\mathrm{OH}$ groups, the increase in CMC follows the sequence: methanol $>$ ethylene glycol $>$ glycerol ${ }^{9}$.

To probe the role of $\mathrm{OH}$ groups on the effect of glucose or glycerol on the CMT in Pluronic P105 aqueous solutions, we plot in Fig. 3 the CMTs against glucose or glycerol content expressed in units of wt\%, mol\%, or $\mathrm{OH}$ group mol\%. Glucose had a stronger effect on CMT compared to glycerol, especially when its concentration is expressed in mol\% or $\mathrm{OH}$ mol\%. For example, the addition of around $20 \mathrm{OH}$ mol\% of glucose in 8 wt\% Pluronic P105 aqueous solution decreased the CMT from 18 to $0{ }^{\circ} \mathrm{C}$, whereas the same amount of $\mathrm{OH}$ groups of glycerol decreased the CMT to $5{ }^{\circ} \mathrm{C}$ (Fig. 3 (c)). These effects can be attributed to the stronger dehydration caused by glucose. It has been reported that: (i) the hydration number (i.e., the average number of water molecules binding to a solute sufficiently strongly as to become part of it) of glucose $(2.8 \pm 0.5)$ is higher than that of glycerol $(2 \pm 0.5)^{35}$, (ii) the addition of glucose to Triton X-100 aqueous solutions lowers the cloud point more than glycerol ${ }^{36}$.

The relative contributions of the $\mathrm{OH}$ groups of glucose or glycerol to the solution properties reported for amphiphile systems are relevant to aqueous solutions of biopolymers (proteins), e.g., the change in preferential hydration (connected to the number of additional water molecules that interact with protein) upon unfolding ribonuclease a and hen egg white lysozyme in aqueous glucose or glycerol solutions ${ }^{37}$, and to the bovine serum albumin gelation temperature changes in aqueous glycerol or sorbitol solutions ${ }^{38}$. It has been shown that the unfolding changes in preferential hydration that are observed in glucose solutions were three times higher than those in glycerol solutions, and were roughly proportional to the $\mathrm{OH}$ group concentration ${ }^{37}$. 
Also it has been reported that the bovine serum albumin gelation temperature increased by $+3^{\circ} \mathrm{C}$ or $+10^{\circ} \mathrm{C}$ by adding $40 \mathrm{wt} \%$ glycerol or sorbitol, respectively, to the aqueous system. When compared in terms of $\mathrm{OH}$ groups, these gelation temperature changes occur at similar concentrations, $12.9 \mathrm{M}$ for glycerol and 13.2 M for sorbitol solutions ${ }^{38}$. This suggests that $\mathrm{OH}$ group numbers alone cannot explain the difference between glucose and glycerol. This can involve a stronger dehydration effect through the combined $\mathrm{OH}$ groups of glucose or glycerol rather than their overall $\mathrm{OH}$ group number in the system.

\section{Thermodynamics of micellization}

The CMT-CMC data for Pluronic P105 in the mixed aqueous solvents (reported in Fig. 2) can be further used to extract information on the thermodynamics of micellization ${ }^{15,30}$. The standard free energy change for the transfer of 1 mole of amphiphile from solution to the micellar phase (free energy of micellization, $\Delta \mathrm{G}^{\circ}$ ), assuming an equilibrium between unimers and micelles, is given by:

$$
\Delta \mathrm{G}^{\circ}=\mathrm{R} \mathrm{T} \ln \left(\mathrm{X}_{\mathrm{CMC}}\right)
$$

where $\mathrm{R}$ is the ideal gas constant, $\mathrm{T}$ the absolute temperature, and $\mathrm{X}_{\mathrm{CMC}}$ the critical micellization concentration (expressed in mole fraction units) at temperature T. $\Delta \mathrm{G}^{\circ}$ needs to be negative for thermodynamically stable micelles to form. The more negative the $\Delta \mathrm{G}^{\circ}$, the stronger becomes the driving force for micellization. With increasing glucose or glycerol content (up to $40 \mathrm{wt} \%$ ) in the solution, $\Delta \mathrm{G}^{\circ}$ becomes more negative at a given temperature (Fig. 4). In the case of ethanol (up to $20 \mathrm{wt} \%$ ), the change of $\Delta \mathrm{G}^{\circ}$ follows the opposite trend.

The standard enthalpy of micellization $\left(\Delta \mathrm{H}^{\circ}\right)$ and the standard entropy of micellization $\left(\Delta \mathrm{S}^{\circ}\right)$ can be calculated from $\Delta \mathrm{G}^{\circ}$ vs. T curves (shown in Fig. 4) using the following equation (assuming that $\Delta \mathrm{H}^{\circ}$ is independent of temperature, which is reasonable for a small temperature 
range):

$$
\Delta \mathrm{G}^{\circ}=\Delta \mathrm{H}^{\circ}-\mathrm{T} \Delta \mathrm{S}^{\circ}
$$

Micelle formation is an enthalpically disfavored process when $\Delta \mathrm{H}^{\circ}$ is positive. In this case, a positive $\Delta \mathrm{S}^{\circ}$ must be the driving force for micellization. The $\Delta \mathrm{H}^{\circ}$ and $\Delta \mathrm{S}^{\circ}$ values are both positive and decrease with increasing glucose or glycerol content: from $258 \mathrm{~kJ} / \mathrm{mol}$ and 0.956 $\mathrm{kJ} / \mathrm{mol} \cdot \mathrm{K}$ in plain water, to $179 \mathrm{~kJ} / \mathrm{mol}$ and $0.721 \mathrm{~kJ} / \mathrm{mol} \cdot \mathrm{K}$ at $30 \mathrm{wt} \%$ glucose monohydrate, respectively. For $30 \mathrm{wt} \%$ glycerol systems, the $\Delta \mathrm{H}^{\circ}$ and $\Delta \mathrm{S}^{\circ}$ values were $180 \mathrm{~kJ} / \mathrm{mol}$ and 0.772 $\mathrm{kJ} / \mathrm{mol} \cdot \mathrm{K}$, respectively (Fig. 5).

The $\Delta \mathrm{H}^{\circ}$ and $\Delta \mathrm{S}^{\circ}$ values decrease with increasing glucose or glycerol contents (Fig. 5) at a constant ratio $\Delta \mathrm{H}^{\circ} / \Delta \mathrm{S}^{\circ}$. This ratio is known as enthalpy-entropy compensation ${ }^{9,39-42}$. According to Lumry and Rajender, the micellization process consists of two parts, the "solvation part" and the "chemical part" ${ }^{39-41}$. The slope of the compensation plot $\left(\Delta \mathrm{H}^{\circ}\right.$ vs. $\Delta \mathrm{S}^{\circ}$ ) provides information on solute-solute and solute-solvent interactions as a measure of the "solvation part" of the micellization process, and the intercept gives information on solute-solute interactions as an index of the effectiveness of the "chemical part" of the micelle formation ${ }^{40,41}$. If both the "solvation part" and the "chemical part" of the micellization process are the same, the $\Delta \mathrm{H}^{\circ} / \Delta \mathrm{S}^{\circ}$ values fall on a straight line ${ }^{42}$. This has been the case for the micellization of three polyoxyethylene(4, 6, or 8) dodecyl ethers in aqueous solutions ${ }^{42}$. As shown in Fig. 8, the $\Delta \mathrm{H}^{\circ} / \Delta \mathrm{S}^{\circ}$ values for the micellization of Pluronic P105 POE-POP-POE block copolymer in aqueous glucose monohydrate or glycerol (0, 20, $30 \mathrm{wt} \%)$ solutions all fall on the same straight line, indicating the same micellization mechanism in both glucose and glycerol solutions.

\section{Micelle solution viscosity}

With increasing temperature, the micelle shape attained by typical POE-containing 
nonionic amphiphiles in aqueous solution may change from spherical to prolonged, because the interfacial curvature becomes less positive due to the dehydration of POE groups ${ }^{43}$. Such micelle shape changes have been connected to changes in the viscosity of the micellar solution $^{44-49}$. For example, the observed increase by a factor of 10 of the specific viscosity of 0.5 - $4 \mathrm{wt} \%$ Pluronic $\mathrm{P} 85\left(\mathrm{EO}_{25} \mathrm{PO}_{40} \mathrm{EO}_{25}\right)$ in $5.5 \mathrm{wt} \% \mathrm{KF}$ aqueous solution with increasing temperature from 35 to $41^{\circ} \mathrm{C}$ has been attributed to a micelle shape change from sphere to rod which was independently established by sedimentation and light scattering measurements ${ }^{44}$. In another example, intrinsic viscosities for Pluronic P85 $\left(\mathrm{EO}_{25} \mathrm{PO}_{40} \mathrm{EO}_{25}\right)$ or $\mathrm{L} 64\left(\mathrm{EO}_{13} \mathrm{PO}_{30} \mathrm{EO}_{13}\right)$ in aqueous salt $(\mathrm{KBr}, \mathrm{KCl}$, or $\mathrm{KF})$ solutions showed a steep rise with increasing temperature at about $10-20{ }^{\circ} \mathrm{C}$ below the cloud point ${ }^{45}$. Non-Newtonian behavior such as shear thickening or shear thinning has also been used as evidence for the existence of rod-like micelles ${ }^{46-49}$. Shear thinning behavior due to rod-like micelle shape has been reported in $50 \mathrm{wt} \%$ sucrose laurate ${ }^{47}$ or cethyltrimethylammonium bromide aqueous solutions ${ }^{48}$, and both shear thinning and shear thickening behavior have been reported in polyoxyethylene(7)-dodecyl, -tetradecyl, or -hexadecyl ether aqueous $\mathrm{NaCl}$ solutions ${ }^{46}$.

Motivated by the above, we probed a possible POE-POP-POE block copolymer micelle shape change in aqueous glucose or glycerol solutions using viscosity measurements. Fig. 7 shows relative viscosity (in the temperature range $7-60{ }^{\circ} \mathrm{C}$ ) for Pluronic P105 (1 or $\left.8 \mathrm{wt} \%\right)$ water solutions, Pluronic P105 (1 or 8 wt\%) - glucose monohydrate (20 or 40 wt\%) - water solutions, and Pluronic P105 (1 or 8 wt\%) - glycerol (20, 40, 60 wt\%) - water solutions. The relative viscosities for binary Pluronic P105 aqueous solutions and ternary Pluronic P105 - 20 wt\% glycerol - water solutions remained almost constant relative to temperature (or decreased slightly). Whereas the viscosities for the systems which have higher glucose or glycerol content increased steeply beyond a certain temperature. For $1 \mathrm{wt} \%$ Pluronic P105 solutions, the 
relative viscosity increases more than ten-fold starting at $50{ }^{\circ} \mathrm{C}$ (in $40 \mathrm{wt} \%$ glucose monohydrate or 60 wt\% glycerol). For 8 wt\% Pluronic P105 solutions, the relative viscosity increases by almost two orders of magnitude, starting at $55{ }^{\circ} \mathrm{C}\left(20 \mathrm{wt} \%\right.$ glucose monohydrate), $40{ }^{\circ} \mathrm{C}(40$ wt\% glucose monohydrate), $55^{\circ} \mathrm{C}$ (40 wt\% glycerol), and $40{ }^{\circ} \mathrm{C}(60 \mathrm{wt} \%$ glycerol).

The lack of change of the relative viscosity relative to temperature is indicative of the preservation of a spherical micelle shape in this temperature range ${ }^{\mathbf{5 , 4 9}} \mathbf{5 0}$, whereas the significant increase in the relative viscosity above a certain temperature may be connected to a micelle shape change from sphere to $\operatorname{rod}^{\mathbf{4 4 - 4 8}}$. In plain water, the Pluronic P105 block copolymer micelles are spherical in this temperature range up to $60{ }^{\circ} \mathrm{C}$. According to the literature, the micelles remain spherical up to $90{ }^{\circ} \mathrm{C}$ for 5 - $8.9 \mathrm{wt} \%$ Pluronic F88 $\left(\mathrm{EO}_{103} \mathrm{PO}_{39} \mathrm{EO}_{103}\right)$ aqueous solutions ${ }^{51,52}$, and up to $95{ }^{\circ} \mathrm{C}$ for 12 wt\% Pluronic F127 $\left(\mathrm{EO}_{99} \mathrm{PO}_{65} \mathrm{EO}_{99}\right)^{53}$. A micelle shape change from sphere to rod occurred above $56{ }^{\circ} \mathrm{C}$ in $10 \mathrm{wt} \%$ Pluronic P94 $\left(\mathrm{EO}_{28} \mathrm{PO}_{48} \mathrm{EO}_{28}\right)$ aqueous solutions ${ }^{54}$, and above $70{ }^{\circ} \mathrm{C}$ in $1 \mathrm{wt} \%$ Pluronic $\mathrm{P} 85\left(\mathrm{EO}_{25} \mathrm{PO}_{40} \mathrm{EO}_{25}\right){ }^{55}$.

The presence of relatively high glucose or glycerol contents enabled Pluronic P105 micelle shape changes to occur in the temperature range $40-55^{\circ} \mathrm{C}$. These temperatures are relatively low compared to the temperatures required for micelle shape transition in the case of aqueous Pluronic P85 and P94 solutions, but are similar to the temperatures at which rod-like POE-POP-POE block copolymer micelles form in water in the presence of salts. Rod-like micelles of Pluronic F88 $\left(\mathrm{EO}_{103} \mathrm{PO}_{39} \mathrm{EO}_{103}\right)$ appeared at $42{ }^{\circ} \mathrm{C}$ by adding $6.1 \mathrm{wt} \% \mathrm{~K}_{2} \mathrm{CO}_{3}{ }^{52}$, of Pluronic P85 $\left(\mathrm{EO}_{25} \mathrm{PO}_{40} \mathrm{EO}_{25}\right)$ at $38{ }^{\circ} \mathrm{C}$ in the presence of $5.5 \mathrm{wt} \% \mathrm{KF}^{44}$, and of Pluronic L64 $\left(\mathrm{EO}_{13} \mathrm{PO}_{30} \mathrm{EO}_{13}\right)$ and $\mathrm{P} 85\left(\mathrm{EO}_{25} \mathrm{PO}_{40} \mathrm{EO}_{25}\right)$ at $15-20{ }^{\circ} \mathrm{C}$ below the cloud point by adding salts such as $\mathrm{KBr}, \mathrm{KCl}$, and $\mathrm{KF}^{45}$.

These micelle changes that occur at relatively low temperatures (around $40{ }^{\circ} \mathrm{C}$ ) are triggered by the addition of solutes. The synergistic effects of glucose or glycerol and 
temperature have been reported in the case of poly(dimethylsiloxane)-graft-polyether copolymer $^{19}$ or polyoxyethylene cetyl ether aqueous solutions ${ }^{4}$. The addition of glucose resulted in an oblate ellipsoidal shape for the micelles formed by a poly(dimethylsiloxane)-graft-polyether copolymer ${ }^{19}$. The addition of glycerol to POE cetyl ether aqueous solution caused an increase of the rod-length of the micelles at first, followed by a decrease when approaching the cloud point temperature ${ }^{4}$. Both these cases have been attributed to the dehydration of POE by glucose or glycerol ${ }^{4,5,6,19,35}$. Therefore, the formation by Pluronic P105 POE-POP-POE block copolymer of rod-like micelles in aqueous glucose or glycerol solutions at elevated temperatures can be attributed not only to the increased hydrophobicity of both POP and POE blocks caused by heating, but also to the further dehydration of POE by glucose or glycerol.

\section{Comparison of glucose and glycerol effects on viscosity relative to the number of $\mathrm{OH}$ groups}

To investigate the role of $\mathrm{OH}$ groups on the effect of glucose or glycerol in the micelle shape change observed in 8 wt\% Pluronic P105 aqueous solutions, we plot in Fig. 8 the temperature at which possible micelle shape changes occurred against the glucose or glycerol content expressed in units of wt\%, mol\%, or $\mathrm{OH}$ group mol\%. Glucose shows more pronounced effects than glycerol on the solution viscosity at the same concentration and temperature. For example, the addition of around $30 \mathrm{OH}$ mol\% of glucose in $8 \mathrm{wt} \%$ Pluronic P105 aqueous solution was necessary for the micelle shape change to occur at $40{ }^{\circ} \mathrm{C}$, whereas around $80 \mathrm{OH}$ mol\% of glycerol was needed in order to have a micelle shape change at the same temperature (Fig. 8 (c)). This can be attributed to the stronger dehydration effect (through mainly $\mathrm{OH}$ groups) of glucose than that of glycerol, the same reason behind the observed trends 
on CMT discussed previously. In fact, the slopes of the micelle shape change temperature and the CMT relative to the glucose or glycerol content are similar (Fig. 8).

This dehydration effect is strong, as attested by the fact that significant relative viscosity increase starting at $40{ }^{\circ} \mathrm{C}$ can still be observed, even following the addition of $10 \mathrm{wt} \%$ ethanol to aqueous solution of 8 wt\% Pluronic P105 and 40 wt\% glucose monohydrate (Fig. 9).

\section{Conclusions}

The effects of glucose, glycerol, or ethanol on the micellization of a representative POE-POP-POE amphiphilic block copolymer (Pluronic P105) in aqueous solutions were investigated in the temperature range $5-60{ }^{\circ} \mathrm{C}$. The work reported here furthers our understanding of self-assembly of amphiphiles in mixed systems and is also relevant in diverse applications such as pharmaceuticals, skin-care, hair-care, detergents, coatings and inks, where (i) product function and viscosity are often intertwined, and (ii) polyethoxylates and polyols (the types of molecules that we considered here) are very common ingredients. This is one of very few studies concerned with effects of glucose on amphiphiles. The findings are also relevant to biological applications where this polyol is often used.

Micelle formation was favored in aqueous solutions containing glucose or glycerol.

Ethanol had the opposite effect and the micelles disappeared above $40 \mathrm{wt} \%$ ethanol. $\Delta \mathrm{H}^{\circ}$ and $\Delta S^{\circ}$ values derived from CMT-CMC data are both positive in the presence of glucose and glycerol, and decrease slightly with increasing solute/solvent content at a constant ratio. The $\Delta \mathrm{H}^{\circ} / \Delta \mathrm{S}^{\circ}$ ratio (known as enthalpy-entropy compensation) falls on the same line for both systems, therefore, both glucose and glycerol affect the micelle formation by the same mechanism.

Significant changes on the relative viscosity suggest that a micelle shape change from sphere to rod takes place at higher content glucose or glycerol aqueous solutions in the 
temperature range 40 to $55{ }^{\circ} \mathrm{C}$. These phenomena are attributed to a dehydration of the POE block of the amphiphile caused by glucose or glycerol, beyond the dehydration effected by the increase in temperature. The temperature above which a micelle shape change occurred decreased with increasing glucose or glycerol content, similarly with the CMT.

Glucose has a greater impact on the CMT and the micellar shape change temperature compared to glycerol, at a given concentration expressed in wt\%, mol\% or $\mathrm{OH}$ mol\%. In fact, the addition of $10 \mathrm{wt} \%$ ethanol (which tends to destabilize the micelles) cannot overcome the effects of $40 \mathrm{wt} \%$ glucose monohydrate on the micelle structure of $8 \mathrm{wt} \%$ Pluronic P105.

\section{Acknowledgements}

K.K. acknowledges Kao Corp. for supporting his research at the University at Buffalo. P.A. is grateful to financial support from the National Science Foundation (CBET 1033878).

\section{References}

(1) Zana, R. "Aqueous surfactant-alcohol systems: A review” Advances in Colloid and Interface Science 1995, 57, 1-64.

(2) Forland, G. M.; Samseth, J.; Gjerde, M. I.; Hoiland, H.; Jensen, A. O.; Mortensen, K. "Influence of alcohol on the behavior of sodium dodecylsulfate micelles" Journal of Colloid and Interface Science 1998, 203 (2), 328-334.

(3) Caponetti, E.; Martino, D. C.; Floriano, M. A.; Triolo, R. "Localization of n-alcohols and structural effects in aqueous solutions of sodium dodecyl sulfate” Langmuir 1997, 13 (13), 3277-3283.

(4) Penfold, J.; Staples, E.; Tucker, I.; Cummins, P. "The structure of nonionic micelles in less polar solvents” Journal of Colloid and Interface Science 1997, 185, 424-431. 
(5) Alexandridis, P.; Yang, L. "SANS investigation of polyether block copolymer micelle structure in mixed solvents of water and formamide, ethanol, or glycerol” Macromolecules 2000, 33 (15), 5574-5587.

(6) Lin, Y.; Alexandridis, P. "Small-angle neutron scattering characterization of micelles formed by poly(dimethylsiloxane)-graft-polyether copolymers in mixed polar solvents” Journal of Physical Chemistry B 2002, 106 (47), 12124-12132.

(7) Pazo-Llorente, R.; Bravo-Diaz, C.; Gonzalez-Romero, E. "Monitoring micelle breakdown by chemical trapping” Langmuir 2003, 19 (22), 9142-9146.

(8) Lee, D. J. "Micellization of sodium dodecyl sulfate in mixtures of methanol, ethylene glycol or glycerol with water” Journal of the Chinese Institute of Chemical Engineers 1996, 27 (1), 49-52.

(9) Lee, D. J.; Huang, W. H. "Enthalpy-entropy compensation in micellization of sodium dodecyl sulfate in water/methanol, water/ethylene glycol, and water/glycerol binary mixtures” Colloid and Polymer Science 1996, 274 (2), 160-165.

(10) Palepu, R.; Gharibi, H.; Bloor, D. M.; Wyn-Jones, E. "Electrochemical studies associated with the micellization of cationic surfactants in aqueous mixtures of ethylene glycol and glycerol” Langmuir 1993, 9 (1), 110-112.

(11) Cantu, L.; Corti, M.; Degiorgio, V.; Hoffmann, H.; Ulbricht, W. "Nonionic micelles in mixed water-glycerol solvent” Journal of Colloid and Interface Science 1987, 116 (2), 384-389.

(12) Ivanova, R.; Lindman, B.; Alexandridis, P. "Modification of the lyotropic liquid crystalline microstructure of amphiphilic block copolymers in the presence of cosolvents" Advances in Colloid and Interface Science 2001, 89-90, 351-382.

(13) Alexandridis, P.; Spontak, R. J. "Solvent-regulated ordering in block copolymers" Current Opinion in Colloid \& Interface Science 1999, 4 (2), 130-139. 
Dai, S.; Sio, S. T.; Tam, K. C.; Jenkins, R. D. "Rheology and aggregation behavior of hydrophobically modified urethane ethoxylate in ethylene glycol-water mixtures" Macromolecules 2003, 36 (16), 6260-6266.

(15) Yang, L.; Alexandridis, P. "Polyoxyalkylene block copolymers in formamide-water mixed solvents: micelle formation and structure studied by small-angle neutron scattering” Langmuir 2000, 16 (11), 4819-4829.

(16) Ding, Y.; Wang, Y.; Guo, R. "Diffusion coefficients and structure properties in the Pluronic F127 / n-C4H9OH / H2O system” Journal of Dispersion Science and Technology 2003, 24 (5), 673-681.

(17) Su, Y.; Wei, X.; Liu, H. "Influence of 1-pentanol on the micellization of poly(ethylene oxide)-poly(propylene oxide)-poly(ethylene oxide) block copolymers in aqueous solutions“ Langmuir 2003, 19 (7), 2995-3000.

Soni, S. S.; Sastry, N. V.; Joshi, J. V.; Seth, E.; Goyal, P. S. "Study on the effects of nonelectrolyte additives on the phase, thermodynamics, and structural changes in micelles of silicone surfactants in aqueous solutions from surface activity, small angle neutron scattering, and viscosity measurements” Langmuir 2003, 19 (17), 6668-6677.

(19) Lin, Y.; Alexandridis, P. "Cosolvent effects on the micellization of an amphiphilic siloxane graft copolymer in aqueous solutions” Langmuir 2002, 18(11), 4220-4231.

(20) Antoniou, E.; Alexandridis, P. "Polymer conformation in mixed aqueous polar organic solvents” Eur. Polymer J. 2010, 46 (2), 324-335.

(21) Khattak, S. F.; Bhatia, S. R.; Roberts, S. C. "Pluronic F127 as a cell encapsulation material: Utilization of membrane-stabilizing agents” Tissue Engineering 2005, 11 (5-6), 974-983.

(22) Jiang, J.; Li, C.; Lombardi, J.; Colby, R. H.; Rigas, B.; Rafailovich, M. H.; Sokolov, J. 
C. "The effect of physiologically relevant additives on the rheological properties of concentrated Pluronic copolymer gels” Polymer 2008, 49 (16), 3561-3567.

(23) Zhou, D.; Alexandridis, P.; Khan, A. "Self assembly in a mixture of two poly(ethylene oxide)-b-poly(propylene oxide)-b-poly(ethylene oxide) copolymers in water" J. Colloid Interface Sci. 1996, 183 (2), 339-350.

(24) Sarkar, B.; Lakshmichand, J.; Alexandridis, P. "Self-assembly of amphiphilic block copolymers in ternary solvent mixtures: Lyotropic liquid crystalline phase behavior and structure” Macromol. Chem. Phys. 2012, 213 (23), 2514-2528.

(25) Sarkar, B.; Ravi, V.; Alexandridis, P. "Micellization of amphiphilic block copolymers in binary and ternary solvent mixtures” J. Colloid Interface Sci. 2013, 390 (1), 137-146.

(26) Mortensen, K. "Structural studies of aqueous solutions of PEO-PPO-PEO triblock copolymers, their micellar aggregates and mesophases: A small-angle neutron scattering study” Journal of Physics: Condensed Matter 1996, 8, A103-A124.

(27) Funari, S. S.; Holmes, M. C.; Tiddy, G. J. T. "Intermediate lyotropic crystal phases in the C16EO6/water system” Journal of Physical Chemistry 1994, 98, 3015-3023.

(28) Sarkar, B.; Lam, S.; Alexandridis, P. "Micellization of alkyl-propoxy-ethoxylate surfactants in water-polar organic solvent mixtures” Langmuir 2010, 26 (13), 10532-10540.

(29) Alexandridis, P. "Poly(ethylene oxide)-poly(propylene oxide) block copolymer surfactants” Current Opinion in Colloid \& Interface Science 1997, 2(5), 478-489.

(30) Alexandridis, P.; Nivaggioli, T.; Hatton, T. A. "Temperature effects on structural properties of Pluronic P104 and F108 PEO-PPO-PEO block copolymer solutions” Langmuir 1995, 11(5), 1468-1476.

(31) Oro, J. R. D. "Role of co-solute in biomolecular stability: Glucose, urea and the water structure” Journal of Biological Physics 2001, 27 (1), 73-79. 
(32) Erdinc, N.; Gokturk, S.; Tuncay, W. "Interaction of epirubicin HCl with surfactants: Effect of $\mathrm{NaCl}$ and glucose” Journal of Pharmaceutical Sciences 2004, 93 (6), 1566-1576.

(33) Kim, C.; Lee, S. C.; Kang, S. W.; Kwon, I. C.; Jeong, S. Y. "Phase-transition characteristics of amphiphilic poly(2-ethyl-2-oxazoline) / poly(epsilon-caprolactone) block copolymers in aqueous solutions” Journal of Polymer Science Part B - Polymer Physics 2000, 38(18), 2400-2408.

(34) Sjoeberg, A.; Karlstroem, G.; Tjerneld, F. "Effects on the cloud point of aqueous poly(ethylene glycol) solutions upon addition of low molecular weight saccharides” Macromolecules 1989, 22(12), 4512-4516.

(35) Zavitsas, A. A. "Properties of water solutions of electrolytes and nonelectrolytes" Journal of Physical Chemistry B 2001, 105(32), 7805-7817.

(36) Wu, J. P.; Gu, T. R. "The effect of organic additives with multipolar group on the cloud point of nonionic surfactants” Acta Chimica Sinica 1995, 53 (10), 958-960.

(37) Hammou, H. O.; del Pino, I. M. P.; Sanchez-Ruiz, J. M. "Hydration changes upon protein unfolding: Cosolvent effect analysis” New Journal of Chemistry 1998, 22(12), 1453-1461.

(38) Baier, S. K.; Decker, E. A.; McClements, D. J. "Impact of glycerol on thermostability and heat-induced gelation of bovine serum albumin” Food Hydrocolloids 2004, 18(1), 91-100.

(39) Lumry, B.; Rajender, S. "Enthalpy-entropy compensation phenomena in water solutions of proteins and small molecules: A ubiquitous property of water” Biopolymers 1970, 9, 1125-1227.

(40) Chen, L. J.; Lin, S. Y.; Huang, C. C. "Effect of hydrophobic length of surfactants on enthalpy-entropy compensation of micellization” Journal of Physical Chemistry B 1998, 102, 4350-4356. 
Aguiar, J.; Molina-Bolivar, J. A.; Peula-Garcia, J. M.; Ruiz, C. C. “Thermodynamics

and micellar properties of tetradecyltrimethylammonium bromide in formamide-water mixtures" Journal of Colloid and Interface Science 2002, 255(2), 382-390.

Chen, L. J.; Lin, S. Y., Huang, C. C.; Chen, E. M. “Temperature dependence of critical micelle concentration of polyoxyethylenated non-ionic surfactants" Colloids and Surfaces A-Physicochemical and Engineering Aspects 1998, 135, 175-181.

Jonstroemer, M.; Joensson, B.; Lindman, B. “Self-diffusion in nonionic surfactant-water systems” Journal of Physical Chemistry 1991, 95(8), 3293-3300.

(44) Jorgensen, E. B.; Hvidt, S.; Brown, W.; Schillen, K. "Effects of salts on the micellization and gelation of a triblock copolymer studied by rheology and light scattering” Macromolecules 1997, 30, 2355-2364.

(45) Bahadur, P.; Pandya, K.; Almgren, M.; Li, P.; Stilbs, P. "Effect of inorganic salts on the micellar behavior of ethylene oxide-propylene oxide block copolymers in aqueous solution” Colloid \& Polymer Science 1993, 271, 657-667.

(46) Toyoko, I.; Motoi, S.; Shoichi, I. “Temperature dependence of viscosity for aqueous $\mathrm{NaCl}$ solutions of nonionic rod-like micelles in dilute and semidilute regimes” Journal of Colloid and Interface Science 1997, 191, 291-302.

(47) Berjano, M.; Guerrero, A.; Munoz, J.; Gallegos, C. "Temperature dependence of viscosity for sucrose laurate/water micellar systems” Colloid \& Polymer Science 1993, 271, 600-606.

Cortes, A. B.; Valiente, M. “The effect of a minimum amount of octyl- $\beta$-D-glucoside on micellar, nematic, and hexagonal phases of the CTAB/glycerol/ water system" Colloid and Polymer Science 2003, 281(4), 319-324.

(49) Guo, L.; Colby, R. H.; Lin, M. Y.; Dado, G. P. “micellar structure changes in aqueous 
mixtures of nonionic surfactants” Journal of Rheology 2001, 45(5), 1223-1243.

(50) Nolan, S. L.; Phillips, R. J.; Cotts, P. M.; Dungan, S. R. "Light scattering study on the effect of polymer composition on the structural properties of PEO-PPO-PEO micelles” Journal of Colloid and Interface Science 1997, 191, 291-302.

(51) Mortensen, K.; Brown, W. "Poly(ethylene oxide)-poly(propylene oxide)-poly(ethylene oxide) triblock copolymer in aqueous solution. The influence of relative block size" Macromolecules 1993, 26, 4128-4135.

(52) Mao, G.; Sukumaran, S.; Beaucage, G.; Saboungi, M. L.; Thiyagarajan, P. “PEO-PPO-PEO block copolymer micelles in aqueous electrolyte solutions: Effect of carbonate anions and temperature on the micellar structure and interaction” Macromolecules 2001, 34, 552-558.

(53) Mortensen, K.; Talmon, Y. "Cryo-TEM and SANS microstructural study of Pluronic polymer solutions” Macromolecules 1995, 28, 8829-8834.

(54) Hvidt, S.; Trandum, C.; Batsberg, W. "Effects of Poloxamer polydispersity on micellization in water” Journal of Colloid and Interface Science 2002, 250, 243-250.

(55) Schillen, K.; Brown, W.; Johnsen, R. M. "Micellar sphere-to-rod transition in an aqueous triblock copolymer system. A dynamic light scattering study of translational and rotational diffusion” Macromolecules 1994, 27, 4825-4832.

(56) Weast, R. (Ed.) Handbook of Chemistry and Physics CRC Press, Cleveland, Ohio, 1974.

(57) McClellan, A. L. Tables of Experimental Dipole Moments Rahara Enterprises, El Cerrito, 1974.

(58) Leo, A.; Hansch, C.; Elkins, D. "Partition coefficients and their uses” Chemical Reviews 1971, 71, 525-616.

(59) Crowin, H.; Albert, L. Substituent Constants for Correlation Analysis in Chemistry and 
Biology John Wiley \& Sons: New York, 1979.

(60) Hansen, Ch. in: Birdi, K. S. (Ed.) Handbook of Surface and Colloid Chemistry, ch. 10 CRC Press, New York, 1997. 
Table 1. Kaizu \& Alexandridis

Table 1. Physicochemical parameters of the solute and solvents used in this study.

\begin{tabular}{|c|c|c|c|c|c|c|}
\hline $\begin{array}{l}\text { Solvent } \\
\text { Solute }\end{array}$ & $\mathrm{m}_{\mathrm{w}}{ }^{\mathrm{a}}$ & $\begin{array}{c}\text { Density }^{\mathrm{b}, \mathrm{c}} \\
\left(\mathrm{g} / \mathrm{cm}^{3}\right)\end{array}$ & $\begin{array}{l}\text { Dielectric } \\
\text { constant }^{\text {b,c }}\end{array}$ & $\begin{array}{c}\text { Dipole } \\
\text { moment }^{\mathrm{d}}\end{array}$ & $\log \mathrm{P}^{\mathrm{e}}$ & $\begin{array}{l}\text { Solubility } \\
\text { Parameter }^{\mathrm{f}} \\
\left(\mathrm{MPa}^{1 / 2}\right)\end{array}$ \\
\hline Water & 18.01 & 0.9982 & 78.5 & 3.11 & -1.38 & 47.8 \\
\hline Glucose & 180.16 & 1.5620 & & 14.1 & -3.29 & \\
\hline Glycerol & 92.10 & 1.2567 & 40.1 & 2.68 & -2.55 & 36.2 \\
\hline Ethanol & 46.07 & 0.7873 & 24.3 & 1.69 & -0.32 & 26.5 \\
\hline
\end{tabular}

${ }^{\mathrm{a}} \mathrm{m}_{\mathrm{w}}$ : molecular weight

${ }^{\mathrm{b}}$ density and dielectric constant values are at $25{ }^{\circ} \mathrm{C}$

${ }^{\mathrm{c}}$ data from Weast [56]

d data from McClellan [57]

${ }^{\text {e }} \log$ P: logarithm of the octanol/water coefficient (data from refs [58] and [59])

${ }^{\mathrm{f}}$ data from Hansen [60] 
Fig. 1. Kaizu \& Alexandridis

\title{
HO- $\left(\mathrm{CH}_{2} \mathrm{CH}_{2} \mathrm{O}\right)_{37}-\left(\mathrm{CHCH}_{2} \mathrm{O}\right)_{58}-\left(\mathrm{CH}_{2} \mathrm{CH}_{2} \mathrm{O}\right)_{37}-\mathrm{H}$ \\ $\mathrm{CH}_{3}$
}

\author{
Pluronic P105
}

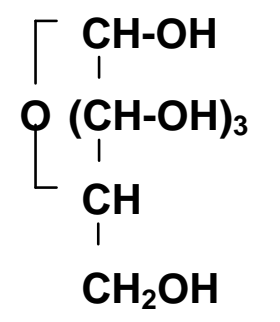

Glucose

\section{$\mathrm{CH}_{2} \mathrm{OH}$}

$\mathrm{CHOH}$

$\mathrm{CH}_{2} \mathrm{OH}$

\section{$\mathrm{CH}_{3} \mathrm{CH}_{2} \mathrm{OH}$}

Glycerol
Ethanol

Figure 1. Chemical structures of the amphiphilic block copolymer and polyols used in this study. 
Fig. 2. Kaizu \& Alexandridis
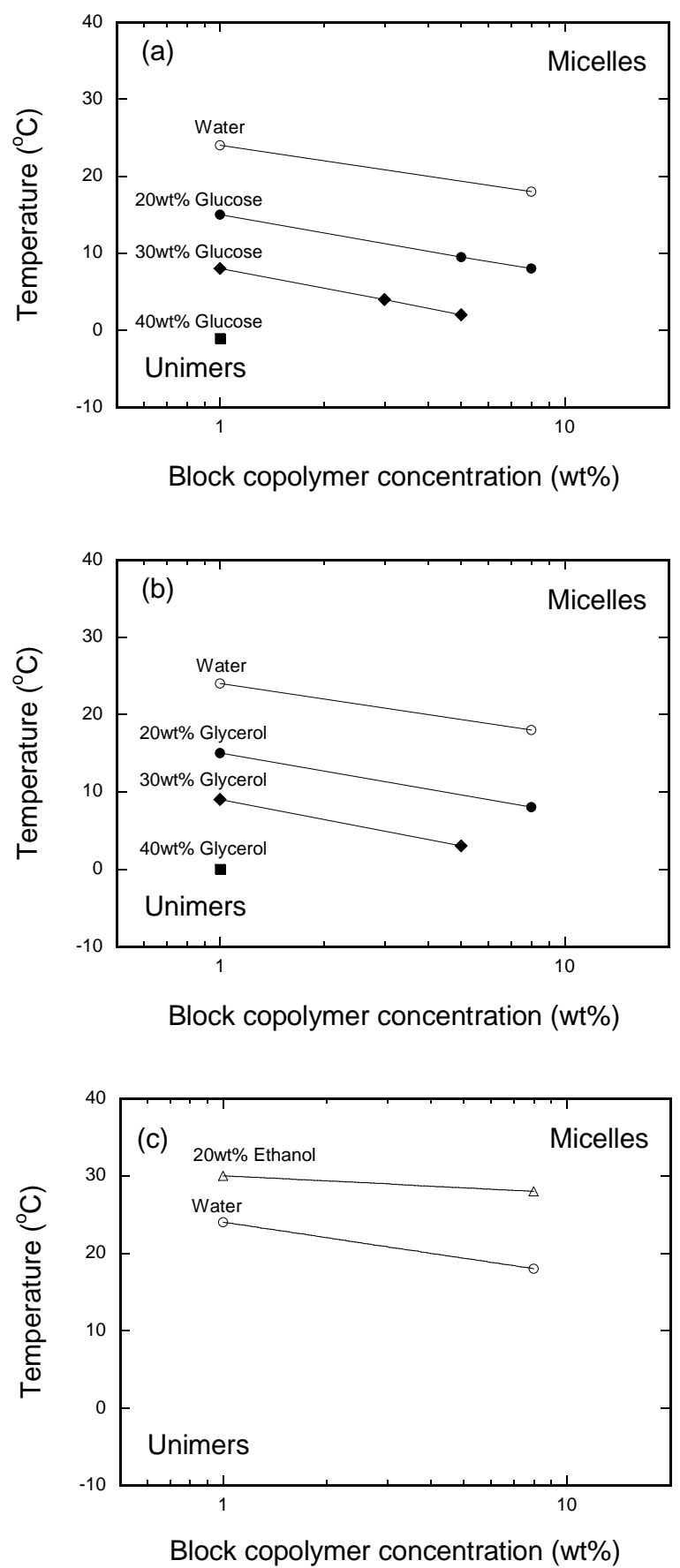

Figure 2. Temperature-concentration micellization boundaries for Pluronic P105 amphiphilic block copolymer in aqueous solutions of (a) glucose monohydrate (0, 20, 30, 40 wt\%), (b) glycerol (0, 20, 30, $40 \mathrm{wt} \%)$, or (c) ethanol (0, $20 \mathrm{wt} \%)$. 
Fig. 3. Kaizu \& Alexandridis
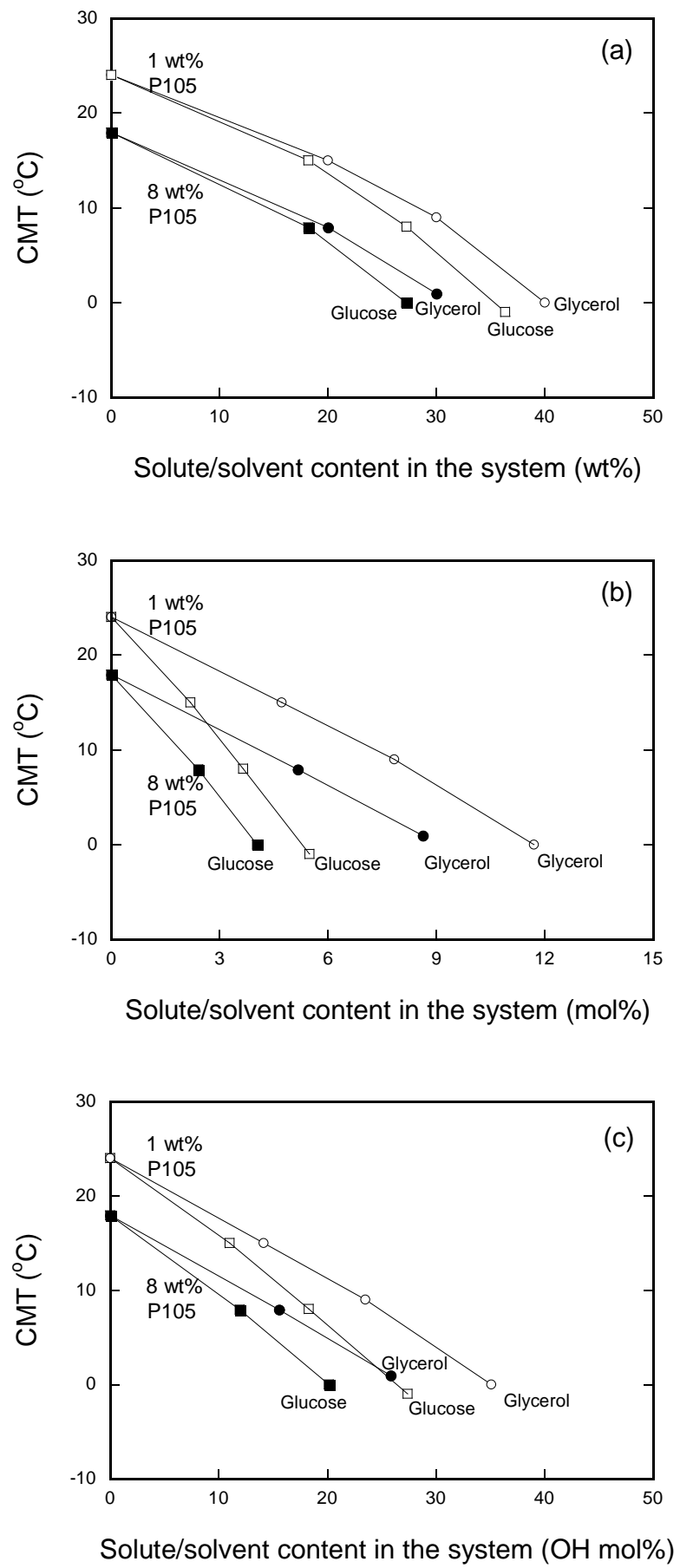

Figure 3. CMT in aqueous Pluronic P105 solutions plotted as a function of glucose or glycerol content, expressed in different units: (a) wt\%, (b) mol\%, and (c) $\mathrm{OH}$ group mol\%. 
Fig. 4. Kaizu \& Alexandridis

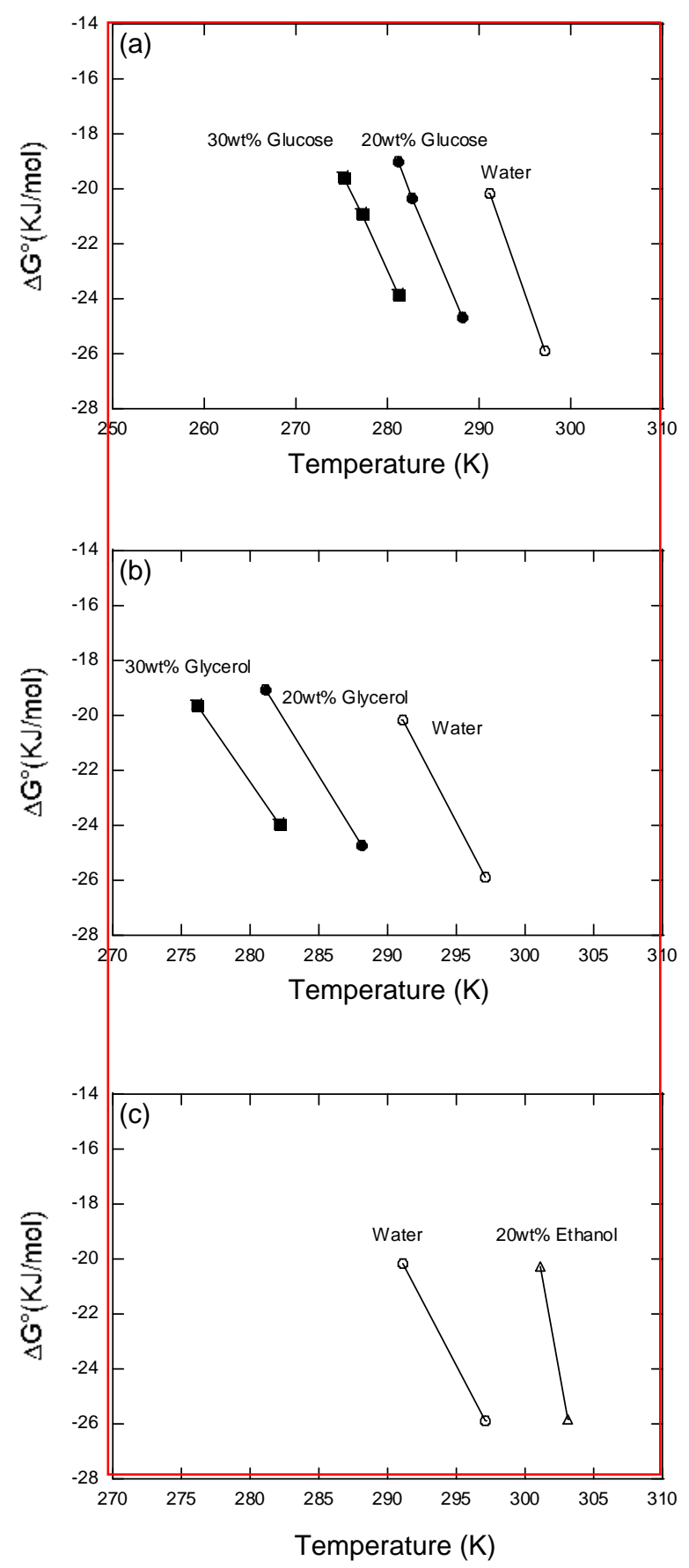

Figure 4. Free energy $\left(\Delta \mathrm{G}^{\circ}\right)$ of Pluronic P105 amphiphilic block copolymer micelle formation in aqueous solutions containing: (a) glucose monohydrate (0, 20, $30 \mathrm{wt} \%)$, (b) glycerol (0, 20, 30 wt\%), or (c) ethanol (0, $20 \mathrm{wt} \%)$. 
Fig. 5. Kaizu \& Alexandridis

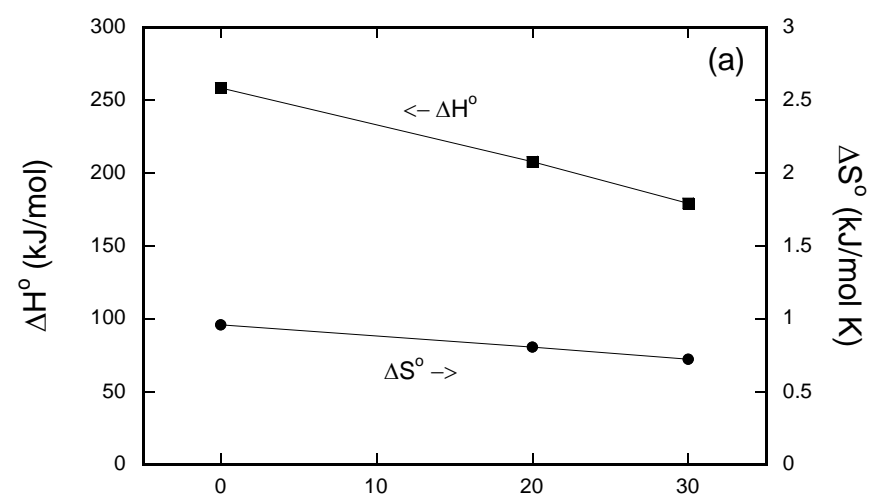

Glucose monohydrate content in solution (wt\%)
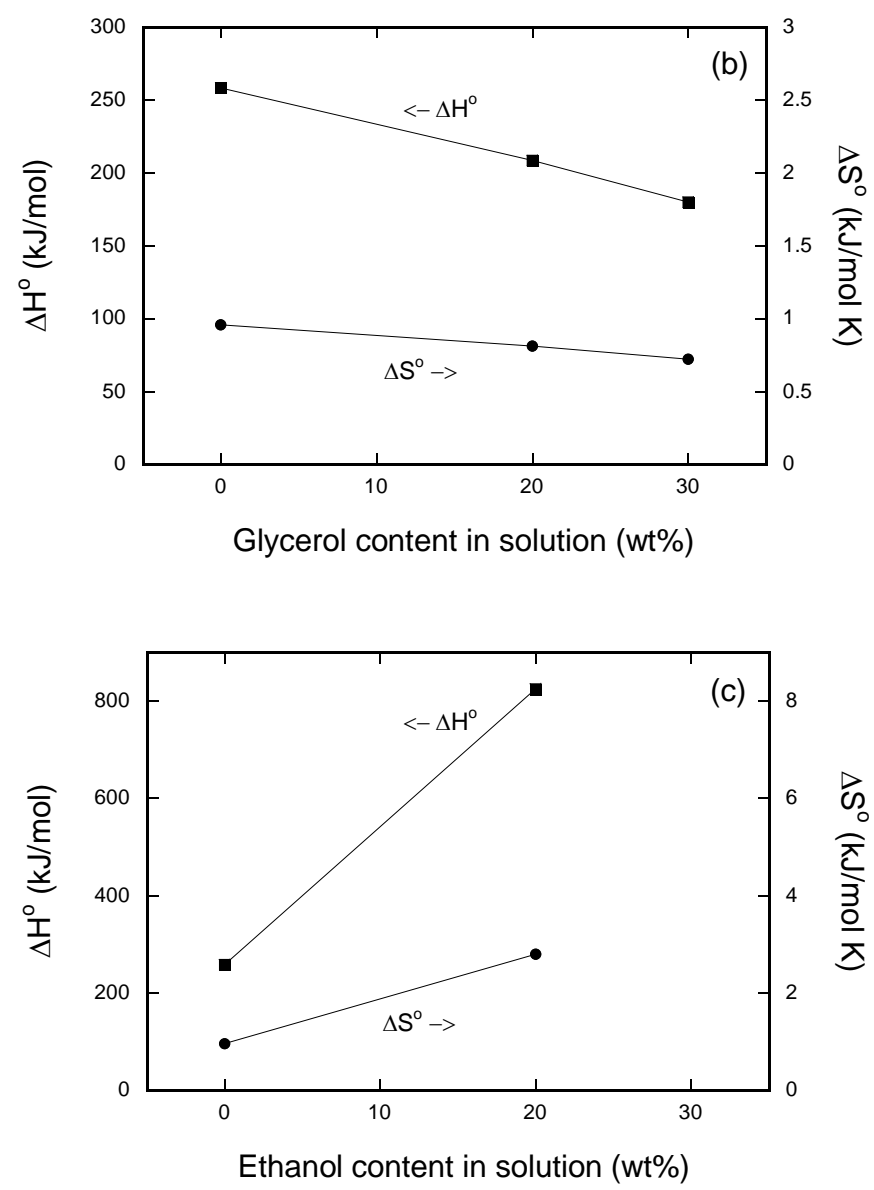

Figure 5. Enthalpy $\left(\Delta \mathrm{H}^{\circ}\right)$ and entropy $\left(\Delta \mathrm{S}^{\circ}\right)$ of Pluronic P105 micellization in aqueous solution plotted as a function of solute or solvent wt $\%$ content: (a) glucose monohydrate $(0,20,30 \mathrm{wt} \%)$, (b) glycerol (0, 20, $30 \mathrm{wt} \%)$, (c) ethanol (0, $20 \mathrm{wt} \%)$. 
Fig. 6. Kaizu \& Alexandridis

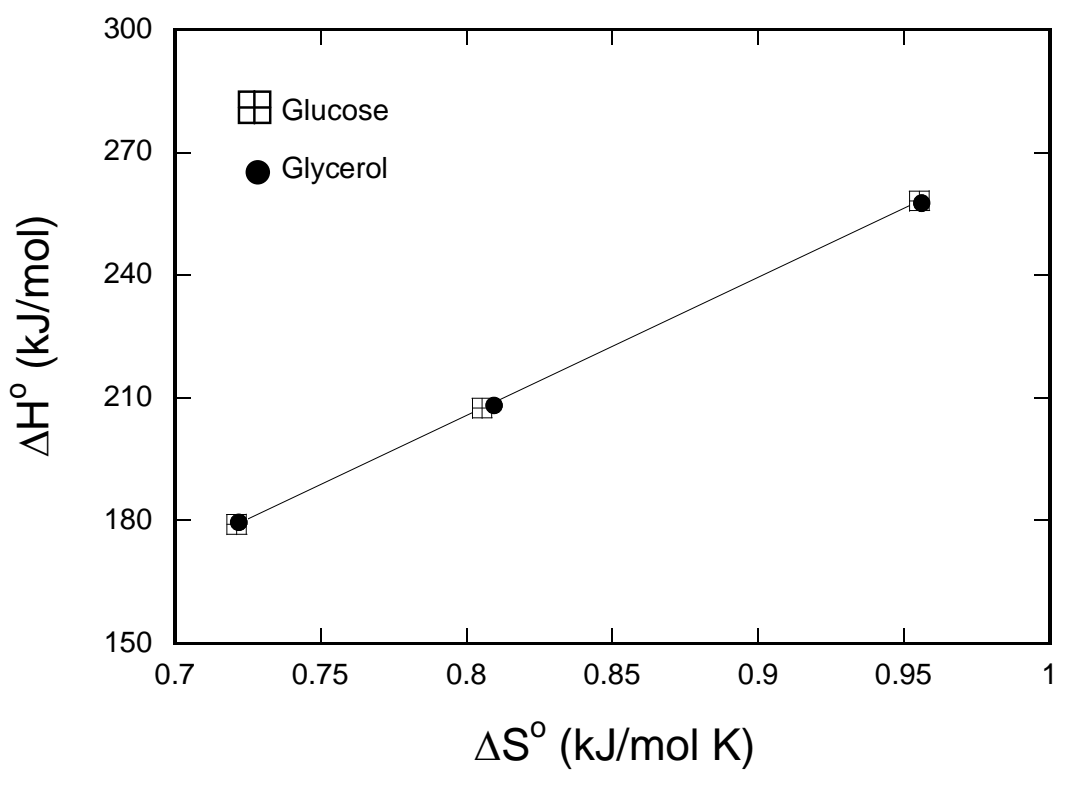

Figure 6. Enthalpy $\left(\Delta \mathrm{H}^{\circ}\right)$ / entropy $\left(\Delta \mathrm{S}^{\circ}\right)$ compensation for the micellization of Pluronic P105 in aqueous solutions containing glucose monohydrate or glycerol (0, 20, $30 \mathrm{wt} \%)$. 
Fig. 7. Kaizu \& Alexandridis

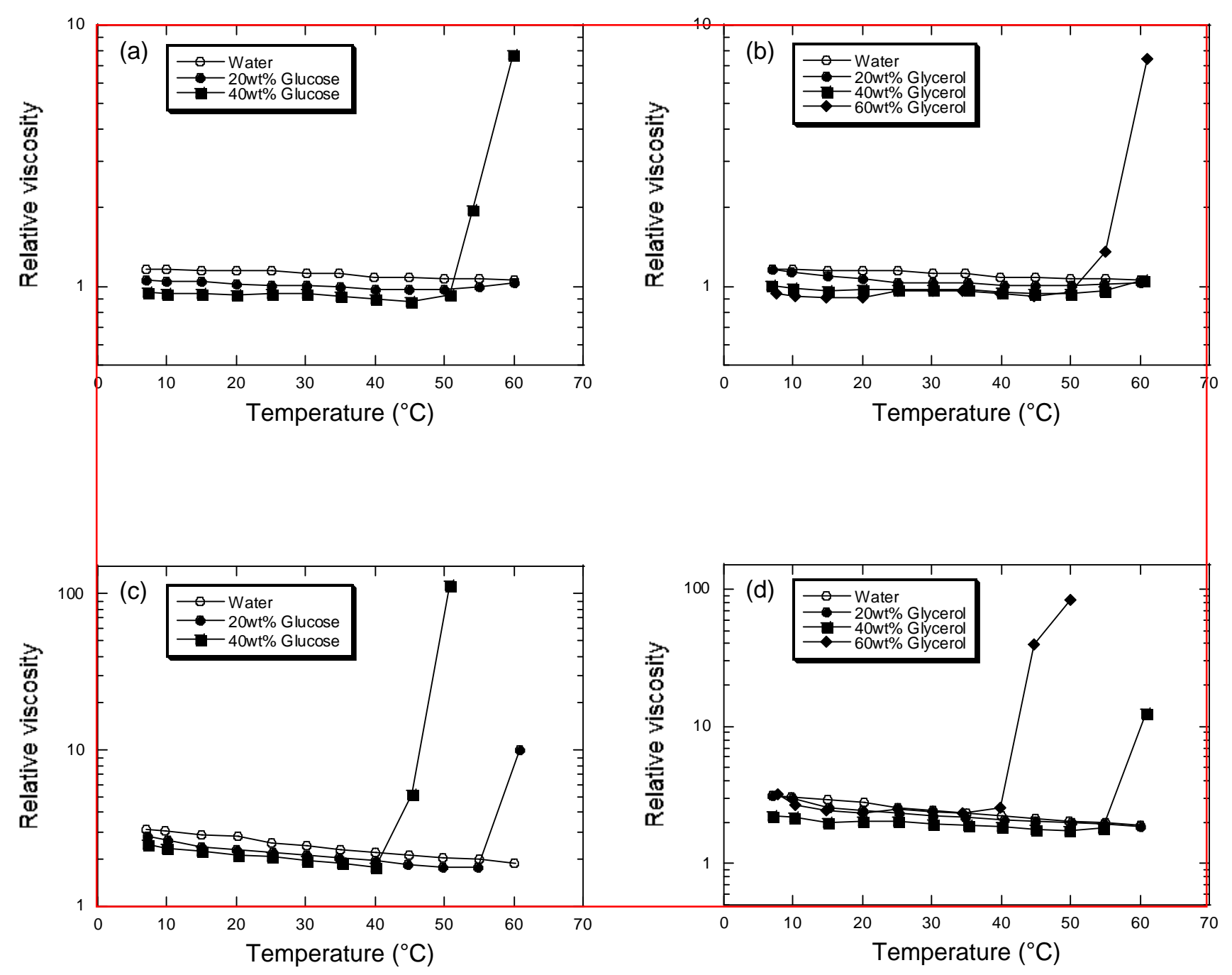

Figure 7. Relative viscosity plotted as a function of temperature for the systems:

(a) Pluronic P105 (1 wt\%) - glucose monohydrate (0, 20, $40 \mathrm{wt} \%)$ - water.

(b) Pluronic P105 (1 wt\%) - glycerol (0, 20, 40, 60 wt\%) - water.

(c) Pluronic P105 (8 wt\%) - glucose monohydrate (0, 20, $40 \mathrm{wt} \%)$ - water.

(d) Pluronic P105 (8 wt\%) - glycerol (0, 20, 40, 60 wt\%) - water. 
Fig. 8. Kaizu \& Alexandridis
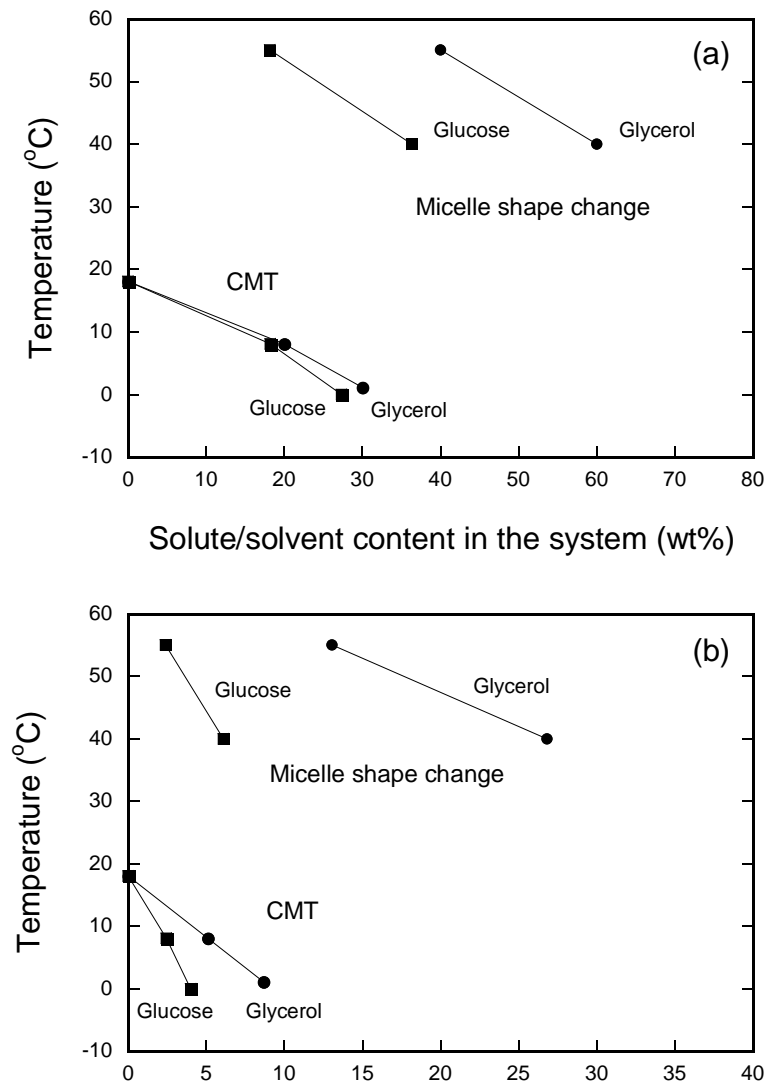

Solute/solvent content in the system (mol\%)

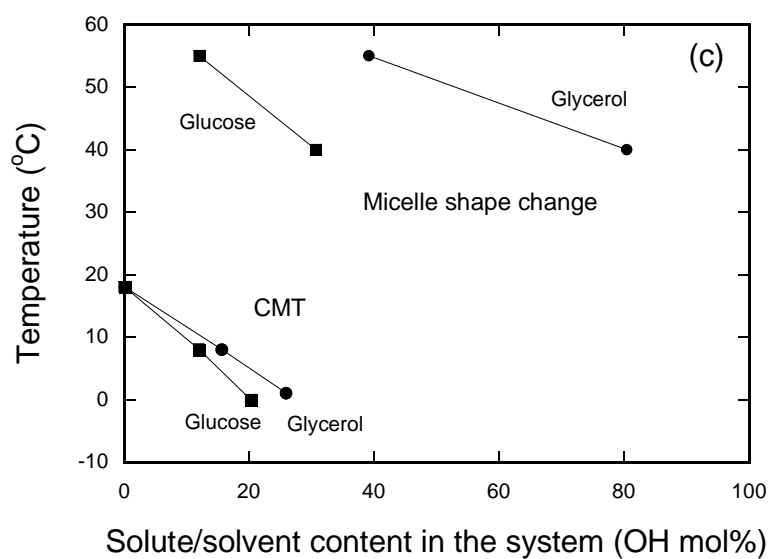

Figure 8. Micelle shape change temperature and CMT of 8 wt\% Pluronic P105 in aqueous glucose or glycerol solutions, plotted as a function of the glucose or glycerol content (expressed in different units): (a) wt\%, (b) mol\%, (c) OH group mol\%. 
Fig. 9. Kaizu \& Alexandridis

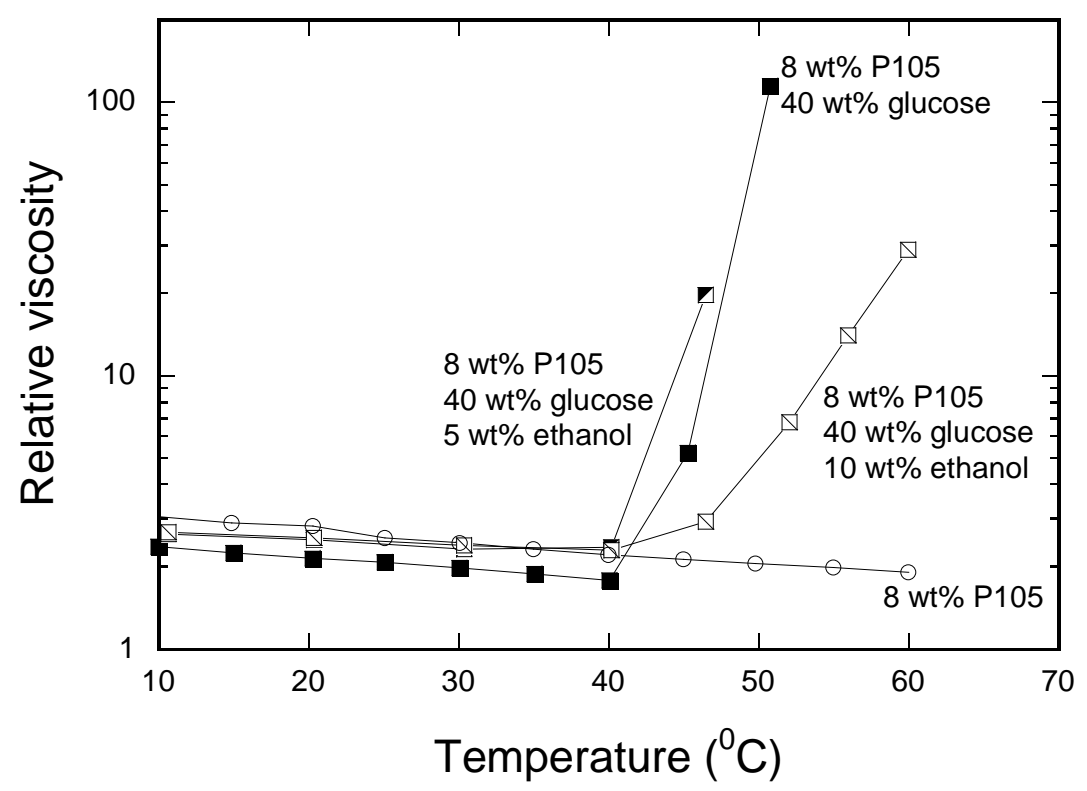

Figure 9. Relative viscosity of Pluronic P105 (8 wt\%) - glucose monohydrate (40 wt\%) - ethanol $(0,5,10 \mathrm{wt} \%)$ - water solutions plotted as a function of temperature. 